NIST Technical Note 1619

\title{
Modeling Human Behavior during Building Fires
}

Erica D. Kuligowski

National Institute of Standards and Technology • U.S. Department of Commerce 

NIST Technical Note 1619

\section{Modeling Human Behavior during Building Fires}

Erica D. Kuligowski

Fire Research Division

Building and Fire Research Laboratory

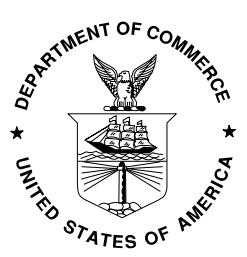

U.S. Department of Commerce Carlos M. Gutierrez, Secretary 
Certain commercial entities, equipment, or materials may be identified in this document in order to describe an experimental procedure or concept adequately. Such identification is not intended to imply recommendation or endorsement by the

National Institute of Standards and Technology, nor is it intended to imply that the entities, materials, or equipment are necessarily the best available for the purpose.

National Institute of Standards and Technology Technical Note 1619 Natl. Inst. Stand. Technol. Tech. Note 1619, 21 pages (December 2008) 


\section{Abstract}

Evacuation models, including engineering hand calculations and computational tools, are used to evaluate the level of safety provided by buildings during evacuation. Building designs and occupant procedures are based on the results produced from these models, including evacuation time results (i.e., how long building occupants will take to evacuate a building). However, most evacuation models focus primarily on calculating and predicting evacuation movement (i.e., how long will it take an occupant to move from his/her initial position to safety), almost ignoring the prediction of behaviors that occupants perform before and during evacuation movement that can delay their safety (e.g., searching for information, fighting the fire, and helping others). Instead of modeling and predicting behavior of simulated occupants, evacuation models and users often make assumptions and simplifications about occupant behavior (i.e., what people do during evacuations) that can be unrealistic and are likely to produce inaccurate results.

A solution to this problem is to generate a robust, comprehensive, and validated theory on human behavior during evacuation from building fires. The social scientific literature can be gleaned to develop these theories, which can then be incorporated into the current evacuation models to accurately simulate occupant behavior during fire evacuations. These models can then achieve more realistic results which will lead to safer, more efficient building design.

The purpose of this paper is to reevaluate our current egress modeling techniques and advocate for the inclusion of a comprehensive conceptual model of occupant behavior during building fires. The paper begins by describing the current state of evacuation modeling of human behavior in fires and identifying gaps in current behavioral techniques. The second part of the paper outlines a general process model for occupant response to physical and social cues in a building fire event.

\section{Keywords}

fire, evacuation, egress, evacuation models, building fires 


\section{Acknowledgements}

Thanks to Kathleen Tierney, Liam Downey, William Grosshandler, Dennis Mileti, and Ross Corotis for their efforts. My appreciation to Richard Peacock, Jason Averill, Anthony Hamins, and Steve Gwynne for providing detailed and insightful suggestions. 


\section{Modeling Human Behavior during Building Fires}

\section{Introduction}

In 2006, structure fires injured over 14000 people and killed over 2700 people in the United States (USFA 2007). In many fires, there may be occupants who are not able to self-evacuate, such as disabled or intoxicated occupants. However, research on fire injuries and deaths shows that over two-thirds of the injured and over half of the dead in building fires could have evacuated; these people were performing activities that delayed their safety, including fighting the fire, attempting to rescue others in the building, and moving to safety under untenable conditions inside the building (Hall 2004).

Evacuation models, including engineering hand calculations (Nelson and Mowrer 2002) and computational tools, can be used to evaluate the level of safety provided by buildings during evacuation. Building designs and occupant procedures are based on the results produced from these models, primarily evacuation time results (i.e., how long building occupants require to evacuate a building). However, most evacuation models focus primarily on calculating and predicting evacuation movement (i.e., how long will it take an occupant to move from his/her initial position to safety), almost ignoring the prediction of behaviors that occupants perform before and during evacuation movement that can delay their exit.

Instead of modeling and predicting behavior of simulated occupants, evacuation models and users often make assumptions and simplifications about occupant behavior that can be unrealistic and can produce inaccurate results. For example, some evacuation models allow for the user to assume that building occupants immediately begin to move to the stairs or exits upon hearing a fire alarm or sensing a fire. This assumption and others like it can represent a scenario that is unlikely to occur in an actual fire event and thereby inappropriately influence the evacuation time calculated by the model. In cases in which assumptions lead to an unrealistic underestimation of evacuation results (i.e., shorter evacuation times), buildings or procedures are designed according to an inadequate life safety design; e.g., insufficient egress routes and/or unsafe procedures for staff and/or occupants. In cases in which assumptions can lead to an unrealistic overestimation of evacuation results (i.e., longer evacuation times), buildings or procedures are designed based on an overestimation of egress needs, which can raise the cost of buildings unnecessarily.

A solution to this problem is to generate a robust, comprehensive, and validated theory on human behavior during evacuation from building fires. The social scientific literature and case studies from disasters and building fires could be employed to develop this theory, which could then be incorporated into the current evacuation models to more accurately simulate occupant behavior during fire evacuations. These models would produce more accurate results and benefit building design. Until a comprehensive theory on occupant behavior is developed for inclusion into evacuation models, costly or ineffective egress or procedural designs may be developed based on the unquantified needs of the evacuating population.

\section{Scope}

The purpose of this paper is to reevaluate our current egress modeling techniques and advocate for the inclusion of a robust, comprehensive, and validated conceptual model of occupant behavior during building fires. This paper begins by describing the current state of evacuation modeling of human behavior in fires and identifying gaps in current behavioral prediction 
techniques. The second part of the paper outlines a model that can predict occupant behavior in response to the interpretations and decisions made regarding physical and social cues in a building fire. Although similar work has identified the lack of behavioral simulation in evacuation models (Santos and Aguirre 2005), no work has been completed to systematically examine research from the evacuation of both buildings and communities to develop behavioral theory for building evacuations.

\section{Building Evacuation Models}

\section{How do building evacuation models work?}

Evacuation models quantify evacuation performance by calculating how long it takes for occupants to evacuate a building. In order to make this calculation, the model attempts to simulate two things: 1 ) the actions that people take and 2) how long it takes to perform each action. In addition to total building evacuation times, evacuation models can provide floor clearing times and the location of the congestion points throughout the building. However, due to the lack of data and theory on occupant behavior/actions, evacuation models significantly simplify the evacuation process and many focus primarily on how long it takes to perform one kind of action: the movement of occupants from their initial positions to the outside of the building. In other words, the current evacuation models primarily focus on the purposive evacuation movement of the occupants and do not simulate additional behaviors that may delay evacuation to safety ${ }^{*}$.

In addition to purposive evacuation movement, occupants are likely to engage in a variety of other activities throughout their evacuation from the building that can delay their movement to safety. Such activities can include information gathering, preparing for the evacuation by gathering their personal belongings, assisting or even rescuing others, alerting others in the building, changing stairs, and fighting the fire. These actions can take place during either period of a building evacuation, either during the pre-evacuation period or the evacuation period. The pre-evacuation period is labeled as the period from the point when the occupant is notified that there is something wrong until s/he begins to travel an evacuation route out of the building. The evacuation period then ends when the occupant has reached a point of safety or outside of the building.

In the models that can account for occupant actions ${ }^{\dagger}$, there are two main methods used to simulate occupant behavior during a building evacuation. One method is for the user to assign a time period of delay/waiting (e.g., a specific period of time, a distribution of times, etc.) to individuals or groups in the simulated building to account for any actions that they might perform during the evacuation (e.g., Simulex ${ }^{\ddagger}$ (Thompson, Wu and Marchant 1996; Spearpoint 2004), EXIT89 (Fahy 2000; 1996), GridFlow (Bensilum and Purser 2002)). Using this method,

\footnotetext{
* Model exceptions to this include buildingEXODUS (Filippidis et al. 2006; Gwynne et al. 1999a) and CRISP (Fraser-Mitchell 1999). These models begin to address behaviors performed by occupants during building fires.

${ }^{\dagger}$ There are a number of models that do not simulate occupant behavior. These are labeled as movement models (Kuligowski and Peacock 2005).

${ }^{\ddagger}$ Certain commercial entities, equipment, or materials may be identified in this document in order to describe an experimental procedure or concept adequately. Such identification is not intended to imply recommendation or endorsement by the National Institute of Standards and Technology, nor is it intended to imply that the entities, materials, or equipment are necessarily the best available for the purpose.
} 
simulated occupants remain stationary in their initial position for a set period of time and then begin purposive evacuation movement once this time period is over. The other method is for the user to assign a specific behavioral itinerary (i.e., a sequence of actions) or a specific action to an individual or group (e.g., CRISP (Fraser-Mitchell 1999), buildingEXODUS (Filippidis et al. 2006; Gwynne et al. 1999a)). Action sequences can be used to simulate behaviors that may interrupt continuous movement, such as searching for information, leaving the stairs, assisting other occupants, and returning to initial locations to retrieve personal or work items. Each action performed is assigned a specific time for each occupant. An example of a behavioral itinerary is the following: Occupant A is assigned a "search and rescue" behavioral itinerary. To perform the search and rescue mission, the model simulates that the occupant moves from Point A (Occupant A's original position) to Point B (another room in the building where the rescue takes place), waits for an assigned period of time at Point $\mathrm{B}$, and then begins purposive evacuation movement from Point B to the stairs.

Both of these methods of simulating behavior during evacuation significantly simplify the behavioral processes that take place during the evacuation. In the first method, assigning a time delay, an emphasis is placed on the time delay itself rather than the decisions, actions, and interactions made by the occupants in response to conditions inside the building. The second method, assigning a behavioral itinerary, begins to simulate decisions and actions made in response to certain conditions during the evacuation, however, the entire behavior or behavioral itinerary is defined by the user before the simulation begins (rather than predicted by the model) and interactions among other simulated occupants is simplified or nonexistent.

There are problems with the approaches used by models to simulate behavior during evacuation. First, no behavior is actually predicted by the evacuation models because behavioral information is provided as prior, pre-programmed assumptions. Behavior is determined by the user or probabilistically by the model based on prescribed information. More importantly, the user prescribes the actions that will occur, or that s/he assumes may occur, in each fire scenario. There is no consistency associated with the prescription of behaviors; this method relies entirely on the user's expertise in understanding occupant behavior in building fires. This is an unrealistic expectation of the user since there is no guidance, comprehensive data set, or theory provided to users about what people actually do during building evacuations.

\section{What are building evacuation models used for?}

Currently, there are over 40 different evacuation models (Kuligowski and Peacock 2005; Gwynne et al. 1999b) available for use in three main types of projects. These projects are safety assessment evaluations (SAE), experimental work, and incident re-creation (Gwynne 2000). Each project type is unique to the purpose of the project, the use of the evacuation model, and the approval process used to evaluate the accuracy of the results, all of which are described below.

During SAE projects, an evacuation model is used to assess the safety of a particular building design and/or egress procedure for the occupants in a building. For these types of projects, the model user is most likely an engineer or a life safety consultant evaluating a new building design or a design from an existing building undergoing a change, such as a use or physical layout. For SAE projects, the user typically runs various evacuation simulations for the building (e.g., occupants travel via different building routes, occupants move at various speeds, etc.) and compares the evacuation simulation results with results from fire modeling simulations. A building is deemed to provide a sufficient level of life safety for occupants if the amount of time needed for evacuation of the building (evacuation modeling results) is less than the time when conditions become untenable for occupants inside the building (fire modeling results). As a final 
step in a SAE project, an authority having jurisdiction must approve the safety analysis made by the engineer, which is sometimes completed through a third-party review process.

Evacuation models are also used in experimental projects. For these projects, the evacuation model is used to explore and investigate conditions that cannot be easily examined otherwise. The model user is often a consultant/engineer evaluating a variety of different designs for the same building or researchers and academics testing hypotheses on the impact of building conditions on results. For experimental projects, the user produces a variety of egress results from the same model from various input conditions. For example, the user can simulate a variety of different egress scenarios using the same model to test different aspects of the building design, such as the size of the stairwell(s), the number of stairs in the building, the width of the corridors, the width, location, and number of exits, etc. In this example, the user may be interested in which designs provide sufficiently fast evacuation times for building occupants. Other examples include the testing of hypotheses related to the impact of fire conditions on people movement through the building.

Evacuation models can also be used in incident re-creation projects. The purpose of these projects is often to determine the cause(s) of actual incident outcomes (e.g., why so many people perished in a particular fire) and/or answer particular questions about the incident itself (e.g., what would have happened if the building was more densely populated during the fire event, if the building had more exits, etc?). Model users are likely to be fire investigators, researchers, engineers, consultants and others charged with answering questions about an actual event. In order to determine causes behind actual incident results, users will attempt to model the actual incident, which may include a series of modeling runs, as close to the actual conditions as possible by using all known conditions from the event. If additional questions are asked (e.g., what-if questions), the user can develop a base-line case and then alter specific conditions in the building to answer the appropriate questions (e.g., adding more people to the building and rerunning the simulation). Evacuation models were used in the investigations of the collapse of the World Trade Center Towers in 2001 (Galea et al. 2008; Averill et al. 2005) and the Rhode Island Nightclub fire (Galea et al. 2008; Grosshandler et al. 2005) to answer specific questions.

A comprehensive theory of human behavior in fire can improve building evacuation models for all three types of projects. However, the generation of a comprehensive theory is most important for SAE and experimental projects. Whereas the user attempts to model behaviors that are already known in incident re-creation project, the user relies on the model for accuracy in simulating an event that has not yet occurred for SAE and experimental projects. Data and theory on human behavior during evacuations is necessary for accurate evacuation modeling results.

\section{What is needed to improve building evacuation models?}

A comprehensive theory of occupant behavior in evacuations from building fires is needed to improve the current building evacuation models. The theory should be able to predict individual behavior and group dynamics that are likely to occur in a building fire, rather than relying on adhoc user-prescription. This would take the burden away from the user to prescribe actions, which can lead to inconsistency and inaccuracy, and actually allow the model to predict behaviors that emerge from situational conditions.

More specifically, a theory should simulate the variety of behaviors performed by occupants in a building fire (e.g., seek information, warn, rescue, and prepare). In mass crowd events, where occupants are densely located in the same area and receive cues together as a group, occupants are likely to respond in similar ways to the cues presented (Purser and Gwynne 2007; Santos and 
Aguirre 2005). In these types of events, most occupants are likely to be influenced by the group throughout the entire evacuation. However, in most building fires, occupants are located in different places throughout the building, many times receiving different instructions or cues from the event. Occupants respond in a variety of ways based on the different cues that are presented to them; and even occupants presented with the same cues are likely to act in different ways (Mileti and Sorensen 1990). This is because occupants' actions vary based on the cues that they perceive, their interpretations of the event and risk, and the decisions that they make about next steps. With this in mind, it is crucial to develop a theory of occupant behavior in building fires based on social/behavior processes.

\section{Theory of Occupant Behavior during Building Fires}

Social scientific theory has acknowledged for over 70 years (Mead 1938) that human action or response is the result of a process. Instead of actions based on random chance or even actions resulting directly from a change in the environment, an individual's actions are frequently the result of a decision-making process. Research in disasters, based on social scientific theory, has led to the development of social-psychological process models for public warning response (Mileti and Sorensen 1990; Perry, Lindell and Greene 1981; Mileti and Beck 1975). These models specify that people go through a process of specific phases, including hearing, understanding, believing, and personalizing the warning, in which they consider aspects of their response before performing an act (Mileti and Sorensen 1990). Additionally, researchers of fire evacuations (Bryan 2002; Feinberg and Johnson 1995; Tong and Canter 1985; Edelman, Herz and Bickman 1980; Breaux, Canter and Sime 1976) have shown that a process involving the phases of recognition and interpretation of the environment influence occupant actions. In these process models, there are specific cue- and occupant-related factors that influence the outcome of each phase of the process (e.g., whether the person hears the warning or interprets the situation correctly). Cue-related factors are described later in this paper and occupant-related factors include demographics (e.g., gender, age, income, education, race, and marital status), previous experiences, and knowledge. An understanding of the behavioral process and the influential factors of each phase can be developed into a conceptual model to predict the types of individual behaviors that are likely to occur in building fires.

The behavioral process for the pre-evacuation or evacuation period of building fires is shown in Figure 1. This process suggests that an occupant's actions are a result of his/her perceptions, interpretations and decisions made based upon the external and internal (occupant-based) cues presented in the fire situation. During a building fire, occupants or groups will begin a behavioral process only when presented with event-related information that interrupts their daily routine. A new behavioral process begins each time an occupant/group receives new information relating to the fire event, and a specific action is likely to occur based on whether the information is perceived, the interpretations of the cue, the situation, and the risk are developed, and the decisions are made on what to do next.

Disaster and fire theory (Mileti and Sorensen 1990; Perry, Lindell and Greene 1981; Edelman, Herz and Bickman 1980; Breaux, Canter and Sime 1976; Mileti and Beck 1975) suggests that individuals engage in a sequence of phases during each behavioral process. In other words, in building fires, interpretation of the cue is possible only if the cue is perceived; an accurate interpretation of the situation is more likely if cues are interpreted accurately; the interpretation of the risk to themselves and others is more likely if the situation is interpreted accurately; and the occupants are more likely to decide on a certain type of action if they perceive cues and formulate 
accurate interpretations of the event and risk. Each phase will be described in further detail in the following section.

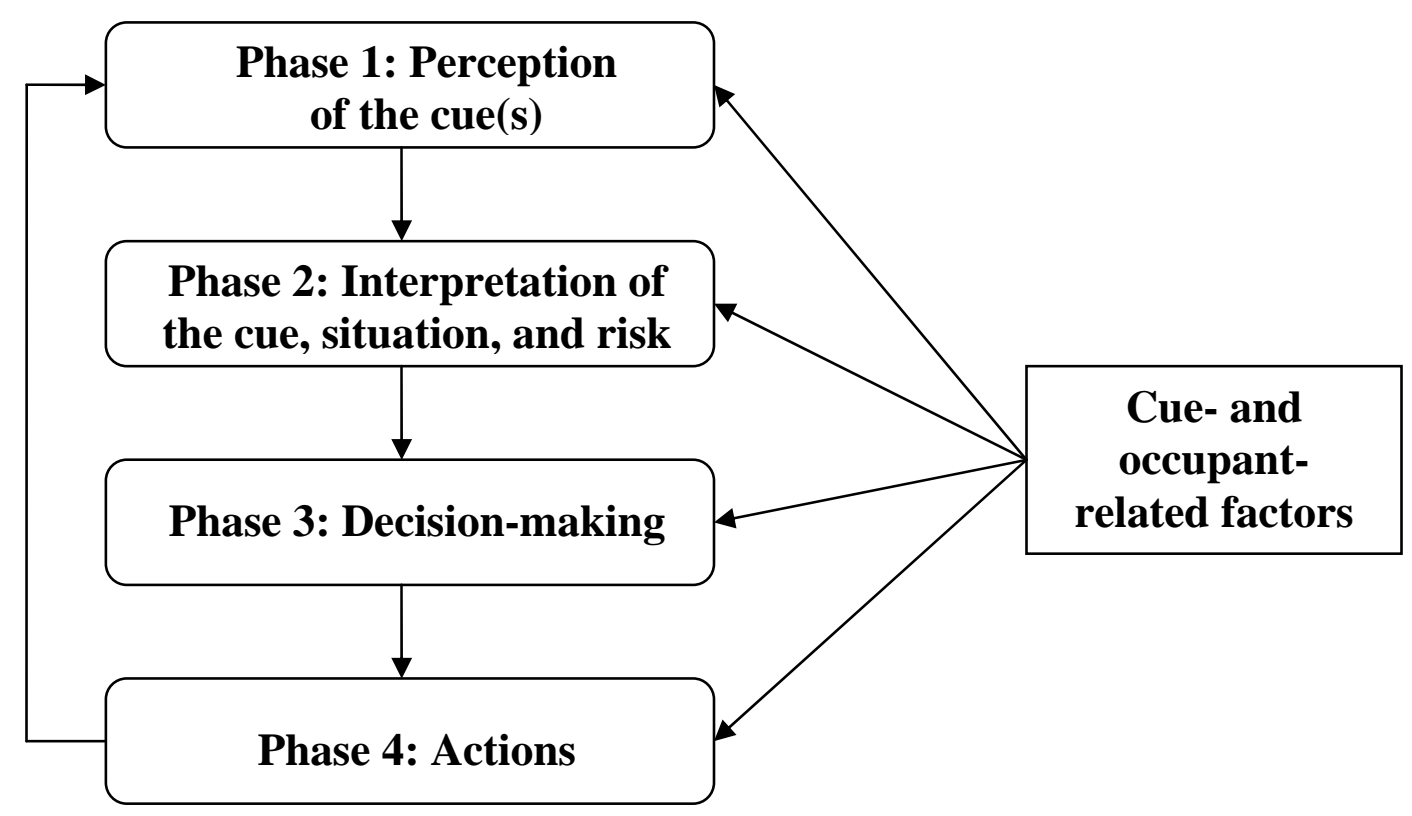

Figure 1: A conceptual model of the behavioral process for building fires

Phase 1 of the behavioral process involves occupants perceiving or receiving external physical and social cues from their environment. In a building fire, occupants are constantly presented with external cues (Brennan 1999). These cues can be physical or social in nature, meaning that they arise from the physical environment or the social environment, respectively. Examples of physical cues in a building fire include flames, smoke, breaking glass, debris, tone alarms, and automatic warnings. Examples of social cues in a building fire include attempted communication from others inside or outside of the building, unofficial or authority-given warnings, and actions taken by the building population. These cues can be presented one by one or several at a time, depending upon the event. The perception phase involves an occupant receiving or noticing cues that makes him/her aware that something in his/her environment has changed (Weick 1995; Starbuck and Milliken 1988; Canter, Breaux and Sime 1980). Physical and social cues produced in a building fire can be perceived by occupants through hearing (e.g., an alarm or authority warning), smelling (e.g., smoke), seeing (e.g., others running), tasting (e.g., sulfur dioxide or hydrogen chloride), and/or touching (e.g., heat).

In the interpretation phase, Phase 2, the occupant or group attempts to interpret the information provided by the cues perceived during the perception phase (Weick 1995; Canter, Donald and Chalk 1992; Turner and Killian 1987). Interpretation can be seen as the process of organizing perceived cues into a framework (Weick 1995); constructing a meaningful story based on an outcome (that is, the cue itself) (Weick 1993); and/or making sense of a situation by imagining what is going on (Rudolph and Morrison 2007; Klein 1999). Interpretation methods include the recall of previously developed behavioral scripts (or a sequence of expected behaviors based upon a situation) (Gioia and Poole 1984), mental simulation (Klein 1999), the use of mental models (Burns 2005), sensemaking (Rudolph and Raemer 2004; Weick 1995; Weick 1993), and collective behavior processes such as milling or intensified interaction (Dynes and Tierney 1994; 
Marx and McAdam 1994; Goode 1992; McPhail 1991; Miller 1985; Berk 1974; Smelser 1962; Turner and Killian 1957). Occupants engage in such methods during fires and other emergencies, because these events create the need for interpretation by interrupting and disrupting normal interaction patterns and creating uncertainty. Behavioral scripts, mental simulation and modeling, and individual sensemaking are interpretation processes performed internally by an occupant to mentally formulate an interpretation. Occupants use behavioral scripts to interpret an event when the cues evoke memories of a previous situation in which a previous interpretation was formed (Gioia and Poole 1984). Mental simulation and modeling allows the occupant to develop cognitive images of what is going on in his/her environment based on the cues that s/he has received. Essentially, the occupant begins to paint a mental picture or story of the event based on the outcome (e.g., the cues).

Group sensemaking and collective behavior involve interaction among occupants to collectively develop an understanding of the emergent situation. In new and/or ambiguous situations (Turner and Killian 1987) and times of urgency (Aguirre, Wenger and Vigo 1998), occupants are likely to interact with others around them. This type of interaction, which is intensified in densely populated buildings, has been documented in a variety of different incidents (e.g., Averill et al. 2005; Bryan 1983) as a means to establish what is going on, define the new situation at hand, and propose and adopt new appropriate norms for behavior (Aguirre, Wenger and Vigo 1998; Turner and Killian 1987). It is through individual and group-based reasoning strategies that occupants can begin to construct meaning from the cues that they perceive in fire situations. In these types of situations, leaders can emerge that suggest interpretations of the event, which can then be incorporated into the occupant's interpretation.

In fires and other extreme events, there are three main interpretation stages: interpreting the cues received, interpreting the situation (i.e. as a fire), and interpreting or defining the risk to the self and/or others. This process is shown in Figure 2. These three interpretation stages do not follow a linear, ordered pattern; instead, interpretive stages can overlap and inform one another in various ways. In fire events, however, it is likely that if occupants interpret a cue correctly (e.g., as a fire alarm, smoke, or an explosion), they are likely to interpret the situation correctly (e.g., as a fire situation), which in turn makes it more likely that they will interpret the situation as risky to themselves and/or to others (Wiegman et al. 1992; Perry and Greene 1983).

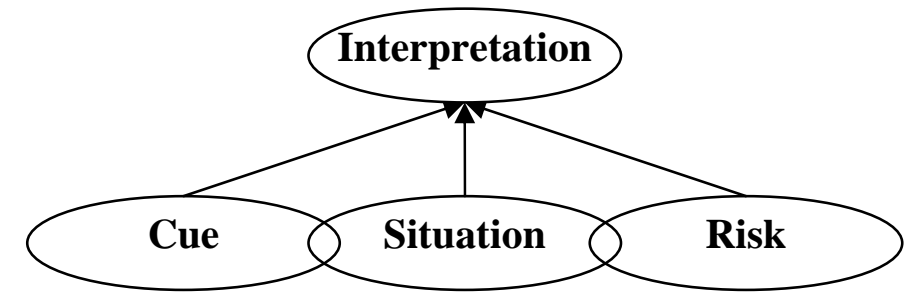

Figure 2: The interpretation phase involves interpreting the cue, the situation, and the risk

If the occupant recognizes the cue, defines the situation correctly, and understands the risk, s/he is likely to perform protective actions in order to begin the evacuation process. Initially, however, occupants are predisposed to interpret the situation as if nothing is wrong, known as normalcy bias (Okabe and Mikami 1982), and that they are not at risk. In a state of normalcy, inaction or waiting is likely to occur. The interpretation of the risk phase is essential to understand, because in order for people to act, they must interpret a situation as dangerous (Aguirre 2005). 
Phase 3 of the behavioral process, decision-making, involves occupants or groups making decisions on what to do next based on their interpretations of the cues, situations, and risks. The decision-making phase is a two-step process in which occupants initially search for options of what to do and then choose one of the options (Gigerenzer and Selton 2001).

The first step in the decision-making phase is to search for options of what to do based on interpretations of the event. Research literature suggests that occupants develop their options by performing mental simulation (Gwynne et al. 1999a; Thompson et al. 1997), similar to the methods of developing interpretations. Mental simulation (Klein 1999) allows an occupant to mentally structure scenarios on what s/he would do and how s/he would do it in the current situation. The search for options becomes the process of mentally developing scenarios of action before actually performing the act.

The search for options of what to do can also occur collectively in groups (Turner and Killian 1987). In addition to interpreting an event, groups work together to plan a coordinated action that will solve the problem presented by the interpretation, if any. Suggestions for actions can come from any member of the group, although leaders are likely to emerge with suggestions of next actions (Connell 2001; Turner and Killian 1987). In the face of uncertainty and time pressure, people are likely to come together, share their interpretations, and define plans for collective action in an event.

Occupants or groups are unlikely to search for a large number of options during the decisionmaking phase. Research suggests that individuals and groups are likely to develop a very small, even narrow range of decision options due to the following conditions: 1) perceived time pressure (Karau and Kelly 1992; Zakay 1993; Janis 1982; Ben-Zur and Breznitz 1981); 2) limited mental resources (Simon 1956; Gigerenzer and Selten 2001; Vaughan 1999); and/or 3) training and knowledge of procedures (Klein 1999; Thompson et al. 1997). Time pressure, likely in a fire event, causes occupants/groups to perceive a fewer number of cues, process the information less thoroughly and in turn, to consider a narrow set of options (Karau and Kelly 1992). Also, people do not expend large amounts of intellectual resources, but rather are likely to envision only the scenarios that they believe are necessary to reach a goal (Gigerenzer and Selten 2001). Finally, research suggests that occupants who are highly trained and/or know of specific procedures will be guided by training and will likely not develop more than one option at a time (Klein 1999).

The second stage in the decision-making phase is to choose one of the options to perform. Rationally-based research claims that occupants will optimize their decision-making by considering all options developed and choosing the best one - known as rational choice strategy (Slovic, Fischhoff and Lichtenstein 1977; Peterson and Beach 1967). In a fire situation, weighing of multiple options is unlikely to occur. Research on decision-making under uncertainty indicates that occupants use a variety of heuristics to make this choice (Klein 1999; Kahneman, Slovic and Tversky 1982). Heuristics are simple rules to explain how individuals make decisions. Whereas some research might view the use of heuristics as a source of bias in decision-making (Tversky and Kahneman 1982), other researchers see heuristics as strengths based on the use of expertise (Flin et al. 1997). Examples of heuristics that occupants employ in choosing options include anchoring or focusing on the first option developed (Kahneman, Slovic and Tversky 1982), choosing the most available option (the easiest to develop or recall) (Kahneman, Slovic and Tversky 1982), comparing all options with each other and choosing one based on the evaluation criteria (Orasanu and Fischer 1997; Janis and Mann 1977; Hammond and Adelman 1976), and satisficing (Simon 1956). 
Satisficing (Slovic, Kunreuther and White 1974; Gigerenzer and Selten 2001) is a method in which an individual chooses the first option that seems to work, though not necessarily the best option overall (Klein 1999). The satisficing heuristic actually combines the processes of option development and option choice together in one step. As the decision-maker develops options, s/he evaluates each one as it is developed and stops developing options when one is deemed to satisfy the search criteria. Whereas the rational choice strategy is more likely to be used when people attempt to optimize a decision (Klein 1999), satificing is more likely to be used in situations with a greater time pressure, dynamic conditions, and ill-defined goals (Klein 1999).

In Phase 4 of the behavioral process, occupants may perform the action that they decided upon in the decision-making phase. If new information/cues are presented before an action is performed, the occupant will discard the current action and begin the behavioral process again. The action involves performing some type of physical act, although the act could be waiting or even inaction, that takes some amount of time to complete. Both summary research (e.g., Bryan 2002; Proulx 2002; Tong and Canter 1985) and research on specific incidents (e.g., Averill et al. 2005; Isner and Klem 1993; Bryan 1982; Best 1977) highlight certain actions in which occupants are likely to engage. These actions, depending upon the situation, can include seeking information, waiting, investigating the incident, alerting others, preparing for evacuation, assisting others, fighting the fire, and searching for and rescuing others. For general purposes, labeling these activities as actions would be appropriate; however, when developing a behavioral model and eventually a computer model, it is important to distinguish between the goals and actions that occupants undertake (Ozel 1985). A goal is an overall objective of the occupant (e.g., fighting the fire) which translates into a series of actions that lead toward achieving that objective (e.g., occupant will travel to the location of the fire extinguisher, then the location of the fire, etc.).

\section{Discussion}

The current evacuation models, as shown in Table 1, either do not simulate occupant behavior at all (Table 1a) or simulate occupant behavior by relying on the user to pre-determine the types of response delays or occupant actions that are likely to occur (Table 1b). In both instances, occupant behavior is simplified in such a way that may inappropriately influence the evacuation time(s) calculated by the model. In one case, occupant behavior is ignored (Table 1a) and in the other case, occupant behavior is simulated either as a distributed delay time or as an imposed action or action sequence that involves isolated movement and delays rather than occupant interaction and group dynamics (Table 1b). In addition, the current behavioral models (Table 1b) require users to provide a large amount of input data on occupant delays and/or action sequences. Most of this information would be impossible to provide since it is required before the evacuation simulation begins, i.e., before the conditions of the scenario are established by the model.

Therefore, this paper proposes the development of a conceptual model (shown in Table 1c) that relies on data and theory imbedded in the evacuation model to predict occupant actions. In the proposed conceptual model, occupant actions are a result of the developing conditions of the simulation (the fire, the building, and the actions of other occupants) which become input into the occupant decision-making process. There are many benefits to the development of a comprehensive conceptual model for the field of human behavior in building fires. The inclusion of a conceptual model into computer evacuation tools will enable a comprehensive model that can actually predict occupant behavior in a building fire and require the user to provide only initial input for the scenario (i.e., information about the fire scenario, the building and the characteristics of the people). A computer model that incorporates a complete behavioral conceptual model would be able to predict situations rather than engineer an outcome based heavily on user input. 
A conceptual model will reduce the burden placed on users of evacuation models and rely on the model to simulate behavior during an event. Additionally, a comprehensive behavioral model of building evacuations illustrates where more data needs to be collected in order to truly understand human behavior in future fire evacuations.

Table 1: Diagrams representing three different evacuation model types

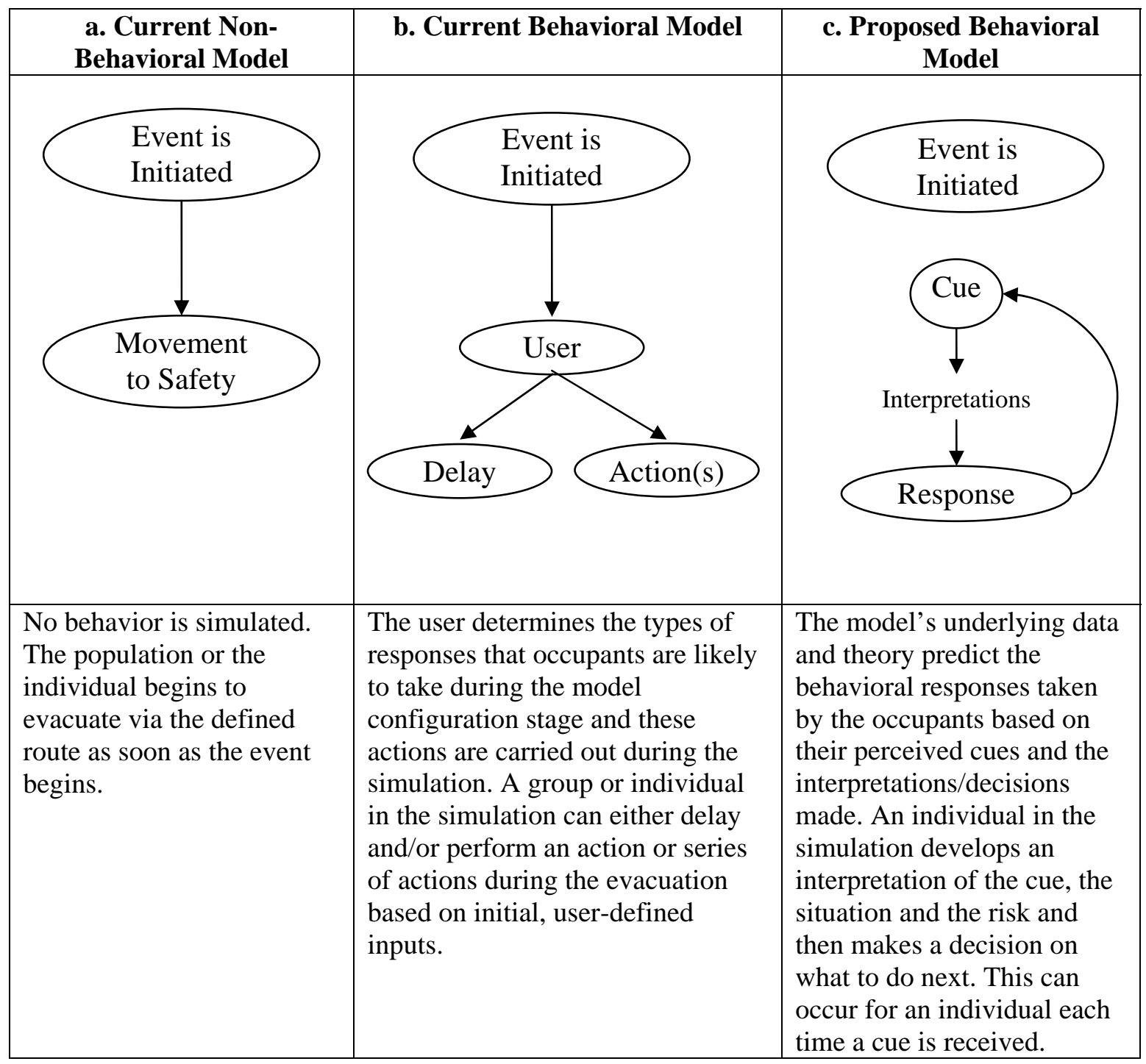

\section{Future Research - How Can We Use This Theory?}

The next step in developing a comprehensive theory is to analyze qualitative data from actual events to identify the various cue-related and occupant-related factors that influence each phase of the behavioral process. An example is provided here: data from an actual event could show that certain cues, for example, a fire alarm, influence a "false alarm interpretation" for certain types of occupants and "only a low amount of perceived risk," which leads to the performance of certain longer-delay activities: e.g., continued working, continued sleeping, milling behavior; whereas instructions to evacuate provided by a member of the fire department produce a 
completely different behavioral process and eventual set of actions. Once these influential factors are linked to specific interpretations, risk perceptions and activities, a behavioral model can be developed. Then, the behavioral theory could be translated into programming language that can be tested and used in current evacuation models. This model will need to be validated, however, with behavioral data from other fire evacuation events.

\section{Conclusion}

Evacuation models are incomplete and oversimplified - they do not account for actual occupant behavior during buildings fires. A solution to this problem is to generate a comprehensive, robust, and validated theory on human behavior during evacuation from building fires.

Behavior during a building fire evacuation is the result of a behavioral process. Each process begins with new cues and information from the physical and social environment. First, cues need to be perceived, then they are interpreted, and then a decision is made as to what action (including inaction) is undertaken. During an evacuation, individuals repeat this process several times as they engage in a variety of different activities both before and during purposive evacuation movement.

The social scientific literature and case studies from fires and disasters can be gleaned to develop this theory, which can then be incorporated to update the current evacuation models to more accurately simulate occupant behavior during fire evacuations. With more accurate and realistic evacuation models and results, engineers and sociologists can develop safer and more costeffective procedures and building designs in the future. 


\section{References}

Aguirre, Benigno E. 2005. "Emergency Evacuations, Panic, and Social Psychology: Commentary on 'Understanding Mass Panic and Other Collective Responses to Threat and Disaster."' Article \#402. Newark, DE: University of Delaware, Disaster Research Center.

Aguirre, B. E., Dennis Wenger, and Gabriela Vigo. 1998. “A Test of the Emergent Norm Theory of Collective Behavior.” Sociological Forum 13:301-320.

Averill, Jason D., Dennis S. Mileti, Richard D. Peacock, Erica D. Kuligowski, Norman Groner, Guylene Proulx, Paul A. Reneke and Harold E. Nelson. 2005. "Federal Building and Fire Safety Investigation of the World Trade Center Disaster: Occupant Behavior, Egress, and Emergency Communications.” Report NCSTAR 1-7. Gaithersburg, MD: National Institute of Standards and Technology. http://wtc.nist.gov/NISTNCSTAR1-7.pdf

Bensilum, M. and David A. Purser. 2002. “Gridflow: An object-oriented building evacuation model combining pre-movement and movement behaviours for performance-based design.” In 7th International Symposium on Fire Safety Science, edited by D. Evans. London, England: Interscience Communications Ltd.

Ben Zur, H. and S. J. Breznitz. 1981. “The Effect of Time Pressure on Risky Choice Behavior.” Acta Psychologica 47:89-104.

Berk, Richard A. 1974. Collective Behavior. Dubuque, IO: WM. C. Brown Company Publishers.

Best, R. L. 1977. Reconstruction of a Tragedy: The Beverly Hills Supper Club Fire. Quincy, MA: National Fire Protection Association.

Breaux, J., David Canter, and Jonathan D. Sime. 1976. "Psychological Aspects of Behaviour of People in Fire Situations.” Pp. 39-50 in International Fire Protection Seminar, $5^{\text {th }}$. Karlsruhe, West Germany.

Brennan, Patricia. 1999. “Modelling Cue Recognition and Pre-Evacuation Response.” Pp. 1029-1040 in Proceedings $-6^{\text {th }}$ International Symposium of Fire Safety Science. London, England: International Association for Fire Safety Science.

Bryan, John L. 2002. “Behavioral Response to Fire and Smoke.” Pp. 3-315 - 3-341 in The SFPE Handbook of Fire Protection Engineering Third Edition, edited by P.J. DiNenno. Quincy, MA: National Fire Protection Association.

Bryan, John L. 1983. An Examination and Analysis of the Dynamics of the Human Behavior in the MGM Grand Hotel Fire. Quincy, MA: National Fire Protection Association.

Bryan, John L. 1982. “Human Behavior in the MGM Grand Hotel Fire.” Fire Journal 76:37-48.

Burns, Kevin. 2005. "Mental Models and Normal Errors.” Pp. 15-28 in How Professionals Make Decisions, edited by H. Montgomery, R. Lipshitz and B. Brehmer. Mahwah, New Jersey: Erlbaum Associates.

Canter, David, John Breaux and Jonathan Sime. 1980. “Domestic, Multiple Occupancy and Hospital Fires.” Pp. 117-136 in Fires and Human Behaviour, edited by David Canter. New York, NY: John Wiley \& Sons.

Canter, David, Ian Donald, and Judith Chalk. 1992. "Pedestrian Behaviour during Emergencies Underground: The psychology of crowd control under life threatening circumstances.” Pp. 135150 in Safety in Road and Rail Tunnels, edited by A. Vardy. Bedford: Independent Technical Conferences Ltd. 
Connell, Rory. 2001. "Collective Behavior in the September 11, 2001 Evacuation of the World Trade Center.” Preliminary Paper \#313. Newark: DE: University of Delaware Disaster Research Center.

Dynes, Russell R. and Kathleen J. Tierney. 1994. Disasters, Collective Behavior, and Social Organizations. Newark, DE: University of Delaware Press.

Edelman, P., E. Herz, and L. Bickman. 1980. "A Model of Behaviour in Fires Applied to a Nursing Home Fire.” Pp. 181-203 in Fires and Human Behaviour, edited by D. Canter. New York, NY: John Wiley \& Sons.

Fahy, Rita F. 2000. “New Developments in EXIT89.” Pp. 153-159 in Proceedings of the $15^{\text {th }}$ Joint Panel Meeting of the U.S./Japan Government Cooperative Program on Natural Resources. Fire Research and Safety, edited by S.L. Bryner. San Antonio, TX.

Fahy, Rita F. 1996. "EXIT89 -- High-rise Evacuation Model -- Recent Enhancements and Example Applications.” Pp. 1001-1005 in Interflam '96, International Interflam Conference -- 7th Proceedings, edited by C. A. Franks and S. Grayson. London, England: Interscience Communications Ltd.

Feinberg, W. E. and Norris R. Johnson. 1995. "Firescap: A Computer Simulation Model of Reaction to a Fire Alarm.” Journal of Mathematical Sociology 20:247-269.

Filippidis, L., E. Galea, S. Gwynne, P. Lawrence. 2006. "Representing the Influence of Signage on Evacuation Behaviour within an Evacuation Model.” Journal of Fire Protection Engineering 16:37-73.

Flin, Rhona, Eduardo Salas, Michael Strub, and Lynne Martin. 1997. Decision Making Under Stress. England, UK: Ashgate Publishing Ltd.

Fraser-Mitchell, J. N. 1999. "Modelling Human Behavior within the Fire Risk Assessment Tool "CRISP." Fire and Materials 23:349-355.

Galea, E. R., G. Sharp, P. J. Lawrence, and R. Holden. 2008. "Approximating the Evacuation of the World Trade Center North Tower using Computer Simulation.” Journal of Fire Protection Engineering 18:85-115.

Galea, Edwin, Zhaozhi Wang, Anand Veeraswamy, Fuchen Jia, Peter J. Lawrence, and John Ewer. 2008. "Coupled Fire/Evacuation Analysis of the Station Nightclub Fire." In the $9^{\text {th }}$ International Symposium on Fire Safety Science.

Gigerenzer, G. and R. Selten. 2001. Bounded Rationality: The Adaptive Toolbox. Cambridge, MA: The MIT Press.

Gioia, Dennis A. and Peter P. Poole. 1984. "Scripts in Organizational Behavior.” Academy of Management Review 9:449-459.

Goode, Erich. 1992. Collective Behavior. New York, NY: Magickal Childe Inc.

Grosshandler, William, Nelson Bryner, Daniel Madrzykowski, and K. Kuntz. 2005. "Report of the Technical Investigation of The Station Nightclub Fire” Report NCSTAR 2: Vol. 1. Gaithersburg, MD: National Institute of Standards and Technology.

Gwynne, Steve M. V. 2000. "The introduction of adaptive social decision-making in the mathematical modelling of egress behaviour.” Ph.D. Thesis, University of Greenwich, London, UK. 
Gwynne, S., E. R. Galea, P. J. Lawrence, M. Owen and L. Filippidis. 1999a. “Adaptive Decision-Making in buildingEXODUS.” Journal of Applied Fire Science 8:265-289.

Gwynne, S., E. R. Galea, P. J. Lawrence, M. Owen, and L. Filippidis. 1999b. “A Review of the Methodologies used in the Computer Simulation of Evacuation from the Built Environment." Building and Environment 34:741-749.

Hall, John R. 2004. “How Many People Can Be Saved from Home Fires if Given More Time to Escape?” Fire Technology 40:117-126.

Hammond, K. R. and L. Adelman. 1976. “Science, Values, and Human Judgment.” Science 194:389-396.

Isner, M. S. and T. J. Klem. 1993. World Trade Center Explosion and Fire, New York, New York, February 26, 1993. Fire Investigation Report. Quincy, MA: National Fire Protection Association.

Janis, I. L. 1982. “Decision Making Under Stress.” Pp. 69-87 in Handbook of Stress: Theoretical and clinical aspects, edited by L. Goldberger and S. Breznitz. New York, NY: The Free Press.

Janis, I. L. and L. Mann. 1977. Decision Making: A psychological analysis of conflict, choice, and commitment. New York, NY: Free Press.

Kahneman, Daniel, Paul Slovic, and Amos Tversky. 1982. Judgment Under Uncertainty: Heuristics and Biases. New York, NY: Cambridge University Press.

Karau, Steven J. and Janice R. Kelly. 1992. "The Effects of Time Scarcity and Time Abundance on Group Performance Quality and Interaction Process.” Journal of Experimental Social Psychology 28:542-571.

Klein, Gary. 1999. Sources of Power: How People Make Decisions. Cambridge, MA: The MIT Press.

Kuligowski, Erica D. and Richard D. Peacock. 2005. "Review of Building Evacuation Models.” Report NIST TN 1471. Gaithersburg, MD: National Institute of Standards and Technology.

Marx, Gary T. and Douglas McAdam. 1994. Collective Behavior and Social Movements. Upper Saddle River, NJ: Prentice-Hall, Inc.

McPhail, Clark. 1991. The Myth of the Madding Crowd. New York, NY: Walter de Gruyter, Inc.

Mead. George Herbert. 1938. The Philosophy of the Act. Edited by C.W. Morris with J.M. Brewster, A.M. Dunham, \& D. Miller. Chicago: University of Chicago.

Mileti, Dennis S. and E. M. Beck. 1975. "Communication in Crisis: Explaining Evacuation Symbolically." Communication Research 2(1):24-49.

Mileti, Dennis S. and John H. Sorensen. 1990. "Communication of Emergency Public Warnings: A Social Science Perspective and State-of-the-Art Assessment.” Oak Ridge, TN: Oak Ridge National Laboratory, U.S. Department of Energy.

Miller, David L. 1985. Introduction to Collective Behavior. Prospect Heights, IL: Waveland Press, Inc.

Nelson, Harold E. and Frederick W. Mowrer. 2002. “Emergency Movement.” Pp. 3-367 - 3-380 in The SFPE Handbook of Fire Protection Engineering Third Edition, edited by P.J. DiNenno. Quincy, MA: National Fire Protection Association. 
Okabe, Keizo, and Shunji Mikami. 1982. "A Study on the Socio-Psychological Effect of a False Warning of the Tokai Earthquake in Japan.” A Paper presented at the Tenth World Congress of Sociology, Mexico City, Mexico, August.

Orasanu, J. and U. Fischer. 1997. "Finding Decisions in Natural Environments: The view from the cockpit.” Pp. 343-358 in Naturalistic Decision Making, edited by C. Zsambok and G. Klein. Mahwah, NJ: Erlbaum.

Ozel, F. 1985. "A Stochastic Computer Simulation of the Behavior of People in Fires: An Environmental Cognitive Approach.” In Proceedings of the International Conference on Building Use and Safety Technology. Washington, DC: National Institute of Building Sciences.

Perry, Ronald W. and Marjorie R. Greene. 1983. Citizen Response to Volcanic Eruptions: The Case of Mt. St. Helens. New York, NY: Irvington Publishers.

Perry, Ronald W., Michael K. Lindell, and Marjorie R. Greene. 1981. Evacuation Planning in Emergency Management. Lexington, MA: Lexington Books.

Peterson, C. R. and L. R. Beach. 1967. “Man as an Intuitive Statistician.” Psychological Bulletin 68:29-46.

Proulx, Guylene. 2002. “Movement of People: The Evacuation Timing.” Pp. 3-342 - 3-365 in The SFPE Handbook of Fire Protection Engineering Third Edition, edited by P.J. DiNenno. Quincy, MA: National Fire Protection Association.

Purser, David A. and Steven M. V. Gwynne. 2007 "Identifying Critical Evacuation Factors and the Application of Egress Models. Pp. 203-214 in Proceedings of the $11^{\text {th }}$ International Interflam Conference, edited by C. A. Franks and S. Grayson. London, England: Interscience Communications Ltd.

Rudolph, Jenny W., J. Bradley Morrison. 2007. "Confidence, Error, and Ingenuity in Diagnostic Problem Solving: Clarifying the Role of Exploration and Exploitation.” Best Paper Proceedings of the Academy of Management Annual Meeting.

Rudolph, Jenny W. and Daniel B. Raemer. 2004. "Diagnostic problem solving during simulated crises in the OR. Anesthesia and Analgesia 98:S34.

Santos, Gabriel and Aguirre, Benigno E. 2005. "Critical Review of Emergency Evacuation Simulation Models.” Pp. 27-52 in Workshop on Building Occupant Movement During Fire Emergencies, edited by R. D. Peacock and E. D. Kuligowski. Gaithersburg, MD: National Institute of Standards and Technology.

Simon, H. A. 1956. "Rational Choice and the Structure of Environments.” Psych. Rev. 63:129-138.

Slovic, Paul, Baruch Fischhoff and Sarah Lichtenstein. 1977. "Behavioral Decision Theory.” Annual Review of Psychology 28:1-39.

Slovic, Paul, Howard Kunreuther and Gilbert F. White. 1974. "Decision Processes, Rationality, and Adjustments to Natural Hazards.” Pp. 187-205 in Natural Hazards, edited by Gilbert F. White. New York, NY: Oxford University Press.

Smelser, Neil J. 1962. Theory of Collective Behavior. New York, NY: The Free Press.

Spearpoint, M. 2004. "Effect of Pre-evacuation Distributions on Evacuation Times in the Simulex Model.” Journal of Fire Protection Engineering 14:33-54. 
Starbuck, W. H. and F. J. Milliken. 1988. “Executives’ perceptual filters: What they notice and how they make sense. Pp. 35-65 in The executive effect: Concepts and methods for studying top managers, edited by D. C. Hambrick. Greenwich, CT: JAI.

Thompson, Catherine M., John A. Forester, Susan E. Cooper, Dennis C. Bley, and John Wreathall. 1997. Pp. 9-13-9-17 in Proceedings of the IEEE Sixth Annual Human Factors Meeting.

Thompson, Peter A., J. Wu, and E. W. Marchant. 1996. "Modelling Evacuation in Multi-storey Buildings with Simulex." Fire Engineering 56:7-11.

Tong, D. and David Canter. 1985. "The Decision to Evacuate: A Study of the Motivations which Contribute to Evacuation in the Event of a Fire.” Fire Safety Journal 9:257-265.

Turner, Ralph H. and Lewis M. Killian. 1987. Collective Behavior. Englewood Cliffs, NJ: Prentice Hall, Inc.

Turner, Ralph H. and Lewis M. Killian. 1957. Collective Behavior. Englewood Cliffs, NJ: Prentice Hall, Inc.

Tversky, Amos and Daniel Kahneman. 1982. “Judgment under Uncertainty: Heuristics and biases.” Pp. 320 in Judgment Under Uncertainty: Heuristics and Biases, edited by D. Kahneman, P. Slovic, and A. Tversky. New York, NY: Cambridge University Press.

Vaughan, Diane. 1999. “The Dark Side of Organizations: Mistake, Misconduct, and Disaster.” Annual Review of Sociology 25:271-305.

Weick, Karl E. 1995. Sensemaking in Organizations. Thousand Oaks, CA: Sage Publications.

Weick, Karl E. 1993. “The Collapse of Sensemaking in Organizations: The Mann Gulch Disaster.” Administrative Science Quarterly 38: 628-652.

Wiegman, Oene, Egli Komilis, Bernard Cadet, Henk Boer, and Jan M. Gutteling. 1992. "The Response of Local Residents to a Chemical Hazard Warning: Prediction of Behavioral Intentions in Greece, France and the Netherlands.” International Journal of Mass Emergencies and Disasters 10:499515.

USFA. 2007. http://www.usfa.dhs.gov/statistics/national/index.shtm

Zakay, Dan. 1993. “The Impact of Time Perception Processes on Decision Making Under Time Stress.” Pp. 59-72 in Time Pressure and Stress in Human Judgment and Decision Making, edited by Ola Svenson and A. John Maule. New York, NY: Plenum Press. 